\title{
RBEP
}

\section{Os espaços experimentais das escolas públicas de Arquitetura do Brasil: realidade ou utopia?}

\author{
Albenise Laverde ${ }^{\mathrm{I}, \text { II }}$ \\ Cláudia Terezinha de Andrade Oliveira ${ }^{\text {III, IV }}$
}

http://dx.doi.org/10.24109/2176-6681.rbep.101i258.4357

\section{Resumo}

Este trabalho está inserido no debate sobre a utilização da experimentação construtiva ao longo da concepção projetual e seu o papel como recurso pedagógico. Trata, mais especificamente, dos espaços e práticas experimentais no contexto acadêmico nacional, objetivando compreender o processo de configuração dos espaços da área técnicoconstrutiva instituídos nas escolas públicas de Arquitetura e Urbanismo, de acordo com as particularidades advindas de diferentes contextos do País, das políticas educacionais e das ações dos atores envolvidos, com a identificação das condições essenciais para que essas práticas sejam implantadas e potencializadas no contexto acadêmico. O trabalho foi desenvolvido com base em pesquisas documentais e por meio de visitas técnicas realizadas em 21 escolas públicas de Arquitetura localizadas em diferentes regiões do País, com entrevistas direcionadas aos principais atores que, atualmente, estão à frente da área estudada. Os dados obtidos possibilitaram contextualizar os desafios enfrentados no ensino da Tecnologia da Construção, que não se resumem ao arranjo físico laboratorial, mas a uma dimensão mais ampla, abrangendo aspectos político-educacionais, estruturais e socioeconômicos, além de questões de fundo, como as relações interpessoais e burocráticas.

Palavras-chave: ensino da tecnologia; espaços experimentais; experimentação construtiva.

\footnotetext{
Universidade Federal de Uberlândia (UFU). Uberlândia, Minas Gerais, Brasil. E-mail: <albenise.laverde@ ufu.br $>$; <https://orcid. org/0000-0003-4711-2053>.

II Doutora em Arquitetura e Urbanismo pela Universidade de São Paulo (USP). São Paulo, São Paulo, Brasil.

III Universidade de São Paulo (USP). São Paulo, São Paulo, Brasil. E-mail: <ctao@ usp.br >; <https://orcid. org/0000-0002-8628-3130>.

IV Doutora em Engenharia de Construção Civil e Urbana pela Universidade de São Paulo (USP). São Paulo, São Paulo, Brasil.
} 


\section{Abstract \\ Experimental workspaces in Brazil's public schools of Architecture: reality or utopia?}

This paper delves in the debate on the use of experimentation in building along the design of the project and its role as pedagogical resource. It approaches, more specifically, the experimental workspaces and practices in the Brazilian academic context. It aims to understand the process used to shape the workspaces related to the fields of technology and construction set in public schools of Architecture and Urbanism, according to the singularities resulting from different contexts in Brazil, educational policies and actions of parties, identifying the essential conditions for those practices to be implemented and strengthened in the academic context. This work has been carried with basis on documentary research and technical visits in 21 public schools of architecture from different regions of the country, counting on interviews with main actors currently in charge of the studied field. Data obtained enable a contextualization of challenges in teaching Technology of Construction, which are not limited to the physical arrangement of the laboratory, but embrace a broader dimension, touching educational, political, structural and socioeconomical aspects, as well as background issues such as interpersonal and bureaucratic relations.

Keywords: building experimentation; experimental workspaces; technology education.

Resumen

Los espacios experimentales de las escuelas públicas de Arquitectura de Brasil: ¿realidad o utopía?

Este trabajo está inserido en el debate sobre la utilización de la experimentación constructiva a lo largo de la concepción proyectual y su papel como recurso pedagógico. Se trata, más específicamente, de los espacios y prácticas experimentales en el contexto académico nacional, con el objetivo de comprender el proceso de configuración de los espacios del área técnico-constructiva implantados en las escuelas públicas de Arquitectura y Urbanismo, de acuerdo con las particularidades provenientes de diferentes contextos del país, de las políticas educativas y de las acciones de los actores involucrados, con la identificación de las condiciones esenciales para que estas prácticas sean implantadas y potenciadas en el contexto académico. El trabajo fue desarrollado a partir de investigaciones documentales y por medio de visitas técnicas realizadas en 21 escuelas públicas de Arquitectura ubicadas en diferentes regiones del país, con entrevistas dirigidas a los principales actores que, actualmente, están al frente del área estudiada. Los datos obtenidos posibilitaron contextualizar los desafíos enfrentados en la enseñanza de la Tecnología de la Construcción, que no se resume en 
el arreglo físico laboratorial, sino a una dimensión más amplia, abarcando aspectos político-educativos, estructurales y socioeconómicos, además de cuestiones de fondo, como las relaciones interpersonales y burocráticas.

Palabras clave: enseñanza de la tecnología; espacios experimentales; experimentación constructiva.

\section{Introdução}

Questões fundamentais como a integração da tecnologia na linguagem plástica da arquitetura e a inserção do conhecimento técnico-científico no saber-fazer do arquiteto continuam sendo recorrentes no exercício do projeto arquitetônico. Inserido nesse debate, este trabalho apresenta os atuais dados sobre a estruturação da área da Tecnologia da Construção ${ }^{1}$ das escolas públicas de Arquitetura e Urbanismo do País e sua infraestrutura laboratorial voltada à experimentação construtiva, de acordo com as particularidades advindas de diferentes contextos, das políticas educacionais e das ações dos atores envolvidos.

Ao analisar historicamente a profissão e o papel da tecnologia na formação do arquiteto, nota-se que sempre estiveram apoiados na multidisciplinaridade, envolvendo dois grandes campos: as artes e as engenharias. No entanto, ao longo do tempo, essas duas áreas passaram a ter caráter dual e a ocupar espaços diferenciados na formação; no Brasil não foi diferente. De acordo com Motta (1977), em relação à educação institucionalizada, o ensino de Arquitetura e Urbanismo teve duas principais vertentes em função da influência que exerceram: uma originária da Escola Nacional de Belas-Artes, no Rio de Janeiro, e outra da Escola Politécnica, em São Paulo. Enquanto no Rio de Janeiro o ensino de Belas-Artes estava integrado à área artística, em São Paulo, de acordo com Ficher (2005), a Arquitetura veio a ser estudada inicialmente como uma das especialidades da Engenharia.

Por volta da década de 1930, ocorreram fatos históricos que provocaram profundas transformações no ensino nos anos subsequentes. Um deles relaciona-se às reformas alinhadas ao Movimento Modernista promovidas por Lúcio Costa em 1931. Paralelamente, ocorreram as primeiras discussões sobre a regularização das atribuições profissionais do arquiteto no País, algo que refletiu diretamente no espaço que a área da tecnologia passou a ocupar na formação do futuro profissional. Esses acontecimentos revelam os constantes embates envolvidos na formação do arquiteto, principalmente no que se refere às atribuições técnicas, em estreita relação com as engenharias, e seu diálogo com a área artística.

Segundo Lopes (2014), no final da década de 1970, a partir de esforços isolados, a defesa da "arte de construir" como atribuição do arquiteto começa a aparecer de modo mais sistemático no âmbito de alguns cursos de Arquitetura e Urbanismo do País, com iniciativas significativas na

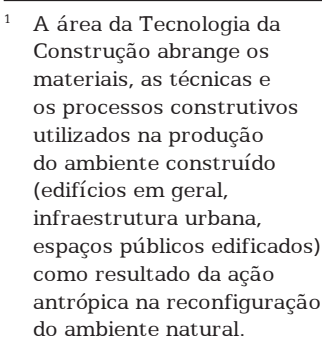


O termo "materialidade" é comumente utilizado para se referir aos aspectos materiais que envolvem a construção da obra arquitetônica, no que se relaciona à estrutura do edifício e aos processos e materiais construtivos.

Os modelos são formas de representação reduzidas do projeto arquitetônico, que podem ser virtuais, desenvolvidos por meio de softwares especiais, ou físicos, na forma de maquetes.

4 As atividades experimentais envolvem experiências com modelos físicos (maquetes e esquemas exploratórios em escala reduzida, utilizando diferentes tipos de materiais) e protótipos (geralmente os protótipos são construídos em escalas próximas à real, devido a isso, essas práticas possibilitam a adoção de materiais construtivos, como madeira, concreto, alvenaria etc.). constituição de práticas didáticas diferenciadas para o ensino tecnológico, tentando restabelecer algum nexo entre arquitetura e construção.

Essas questões têm sido direcionadas, atualmente, tanto para o estudo da materialidade ${ }^{2}$ como para as novas formas de representação do objeto arquitetônico, a partir da inserção de novas ferramentas investigativas ao longo do desenvolvimento projetual, principalmente as de base computacional. Sobre essas transformações, Grande (2000) faz considerações pertinentes a respeito da exaltação do poder representacional da tecnologia computacional em relação à sua aplicação construtiva, que pode levar à construção de sedutores modelos ${ }^{3}$ espaciais tridimensionais, mas que se revelam majoritariamente inócuos na possibilidade de se tornarem materializáveis.

Essas preocupações vão ao encontro dos atuais questionamentos sobre os rumos do ensino da Tecnologia da Construção nos cursos de Arquitetura e Urbanismo, e adquirem dimensões cada vez mais amplas diante do pseudoentendimento de que novas ferramentas investigativas, partindo de processos computadorizados, poderão substituir, em sua totalidade, a sensibilidade construtiva adquirida a partir de atividades cognitivas.

Devido à natureza multidisciplinar da formação do arquiteto, o diálogo entre as principais áreas de concentração torna-se importante, são elas: Projeto, Urbanismo, Tecnologia da Arquitetura, História e Representação. A Tecnologia da Construção está inserida em Tecnologia da Arquitetura, ao lado de subáreas como Sistemas Estruturais, Conforto Ambiental e Instalações Prediais (hidrossanitárias e elétrica). As deficiências advindas da falta de interação da tecnologia com as áreas podem ser vistas em Tamashiro (2010), ao constatar que a gradual diminuição na vivência com experiências relacionadas à materialidade e ao baixo entendimento técnico-construtivo do alunado, principalmente na área da Tecnologia da Construção, tem provocado prejuízos no ensino do desenho arquitetônico (área da Representação), resultando em desenhos inexpressivos ou representados de forma incoerente com a realidade material.

Bayl-Smith (2011) apresenta indícios sobre as mudanças no ensino da Tecnologia da Construção em diversos cursos de Arquitetura de universidades internacionais e, assim como Grande (2000), faz questionamentos sobre a inserção de "novas" tecnologias nos processos voltados à área construtiva nos cursos, além de indagar se experiências atualmente exploradas conseguem atingir o grau científico/tecnológico sobre a materialidade construtiva, ou permanecem no campo formal/ criativo, apresentando uma falsa noção sobre os princípios construtivos reais.

A Figura 1 apresenta algumas atividades experimentais ${ }^{4}$ na área técnico-construtiva desenvolvidas em escolas internacionais. Baseando-se nelas é possível compreender alguns aspectos que caracterizam os espaços utilizados para o desenvolvimento de atividades dessa natureza, cujo caráter exploratório sobressai em relação à instrução básica, resultando em experiências criativas advindas de processos cada vez mais complexos, exigindo o envolvimento de equipes multidisciplinares. 


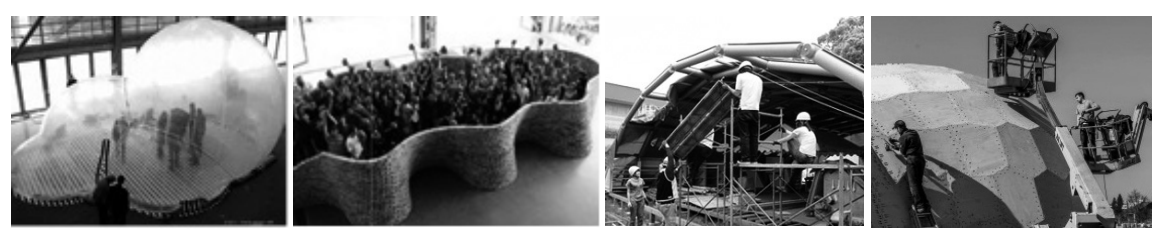

Figura 1 - Exemplos de atividades experimentais realizadas em escolas internacionais de arquitetura

Fonte: -Elaboração própria, com base em Les Grands... (2017); Vaccari (2013, p. 17); University of Stuttgart (2014).

Nota: a) e b) Les Grands Ateliers - Grenoble - Atividades realizadas entre 2008 e 2009 e entre 2011 e 2012, respectivamente; c) Faculdade de Artes e Design da Universidade de Kioto, 2013; d) TU Stuttgart -Institute of Building Structures and Structural Design (ITKE).

Em relação às experiências nacionais, a escassez de atividades voltadas à experimentação construtiva nas escolas brasileiras, segundo Grazzia (1999), foi detectada pela Comissão de Especialistas em Arquitetura e Urbanismo (Ceau) como uma das mais notáveis falhas na formação do arquiteto e urbanista. Ainda de acordo com o relatório apresentado pela comissão, "a dinâmica do processo de ensino/aprendizagem requer a utilização de múltiplas formas de apropriação do conhecimento, e não se limita à oferta de disciplinas ministradas em sala de aula". Em 1994, a segunda e última avaliação realizada pela Ceau forneceu dados detalhados sobre a infraestrutura das escolas nacionais, com declarações preocupantes sobre as condições encontradas, inclusive nas escolas públicas. Sobre esse cenário, chamam atenção algumas considerações de Santos Júnior (2001) sobre o primeiro levantamento da Ceau em 1974, ao relatar que, de maneira geral, os cursos nas instituições públicas eram os que apresentavam menos deficiências quanto às instalações do que a maioria das instituições. De acordo com o autor, em 1994 ocorreu uma inversão. Observou-se o sucateamento das instalações dos cursos sediados nas instituições públicas, decorrente da falta de manutenção, provavelmente de carência, inadequação ou má distribuição das áreas.

Entre 2013 e 2017, foi desenvolvido o trabalho de doutorado intitulado "Os espaços experimentais ${ }^{5}$ das escolas públicas de arquitetura do Brasil: realidade ou utopia?", com levantamento sobre a atual configuração da infraestrutura das escolas públicas de arquitetura e os principais desafios relacionados ao ensino da Tecnologia da Construção. O título seguinte apresenta detalhadamente os dados levantados e analisados nesta pesquisa.

\section{Os espaços experimentais das escolas públicas de arquitetura do Brasil}

Ao analisar a atual estruturação da área da Tecnologia da Construção em diferentes escolas públicas brasileiras, foi possível contextualizar os desafios enfrentados, que não se resumem ao arranjo físico laboratorial, mas

\footnotetext{
O termo espaços

experimentais foi adotado nesta pesquisa por contemplar, de forma abrangente, os diferentes tipos de infraestrutura que dão suporte às atividades experimentais, diante da inexistência em fontes bibliográficas de conceituações que caracterizassem e, posteriormente, classificassem os tipos de infraestrutura como: canteiro experimental, canteiro de obras, laboratório de tecnologias construtivas - de materiais, estruturas, modelos -, marcenaria etc
} 
6 Para atender aos procedimentos éticos em pesquisa, foi adotado o uso do Termo de Consentimento Livre e Esclarecido junto aos atores entrevistados. Outra medida adotada no processo de análise das informações foi a apresentação dos dados sintetizados de forma geral, não sendo possível estabelecer ligação direta entre os entrevistados e os dados fornecidos, de forma a preservar o anonimato desses.

Em relação ao ano de início da pesquisa, 2013. a uma dimensão mais ampla, pois abrangem aspectos político-educacionais, estruturais e socioeconômicos. Uma simples abordagem quantitativa não possibilitaria que se compreendessem questões de fundo, que dizem respeito à natureza das relações interpessoais e burocráticas que envolvem a temática, difíceis de serem captadas por meio de instrumentos somente descritivos, como a aplicação de questionários. Dessa forma, o trabalho adotou a análise qualitativa, algo possível somente por meio de visitas técnicas in loco, com entrevistas direcionadas aos principais atores à frente da área estudada, somando, ao todo, 67 profissionais pertencentes a 21 escolas públicas do País e entidades de classe. ${ }^{6}$

Foi realizado, inicialmente, o levantamento das escolas públicas de Arquitetura do País, por meio de consulta aos dados fornecidos pelo Ministério da Educação (MEC), organizados em um mapa, de acordo com a Figura 2 .

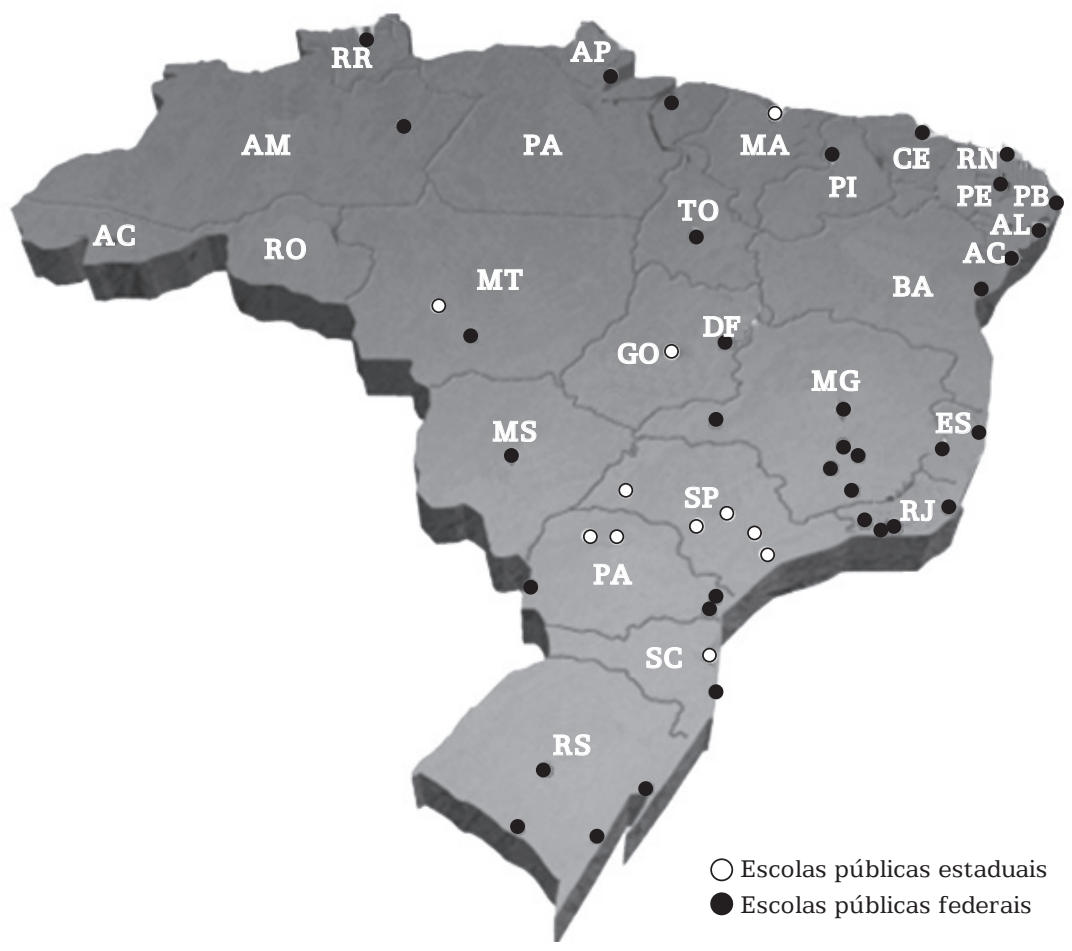

Figura 2 - Mapa do Brasil com a localização dos cursos de Arquitetura e Urbanismo inseridos em instituições públicas

Fonte: Elaboração própria, com base em dados de Brasil. MEC ([2007]).

Ainda sobre os critérios para a escolha das instituições públicas a serem visitadas, destaca-se a data de implantação dos cursos. Ressalta-se que as escolas implantadas nos últimos dez anos ${ }^{7}$ não foram contempladas neste trabalho. Tal recorte temporal deve-se ao fato de as implantações dos espaços para o desenvolvimento das atividades de experimentação requererem um período longo para sua consolidação. 
Foi considerado o tipo de amostragem não probabilística, correspondente a uma técnica que não utiliza seleção aleatória, mas confia no julgamento pessoal do próprio pesquisador. Esse tipo de amostragem, de acordo com Selltiz et al. (1975) e Mattar (1996), não tem como objetivo a generalização dos resultados obtidos, mas dá a chance de obter certa ideia da variedade de elementos existentes no conjunto pesquisado, pela intenção em considerar suas particularidades regionais e históricas de implantação e utilização.

Foi selecionado um conjunto de escolas que tivesse representatividade regional e também atendesse às considerações sobre os aspectos históricos, contemplando escolas implantadas antes da década de 1960, ao longo da década de 1960, 1970, 1980, até o final da década de 1990. Dessa forma, dentro do universo de 33 escolas brasileiras de Arquitetura e Urbanismo inseridas em instituições públicas e implantadas até 2002, 21 delas foram contempladas pela pesquisa, de acordo com o Quadro 1.

A sistematização das informações foi realizada com base na triangulação de dados provenientes de documentos sobre cada curso (teses, projetos pedagógicos, sites institucionais, além de livros e artigos científicos sobre cada escola, quando disponibilizados), contrapondo os dados obtidos in loco ao longo das entrevistas e visitas técnicas para conhecer a infraestrutura, organizados de acordo com: i) o histórico de implantação e desenvolvimento do curso; ii) a estruturação curricular da área da Tecnologia da Construção; iii) o quadro docente da área estudada; iv) a caracterização das práticas didáticas e infraestrutura laboratorial na área da Tecnologia da Construção; v) a pós-graduação - identificação das linhas de pesquisa e infraestrutura disponível; e vi) as considerações gerais sobre particularidades encontradas.

Sobre a cultura organizacional presente nas universidades públicas, Trigueiro (1999) considera que a autonomia de docentes e dirigentes acadêmicos poderia levar as universidades a desenvolverem resistências a quaisquer interferências externas. A referida autonomia está diretamente associada à liberdade de escolha do enfoque disciplinar e curricular e, indiretamente, à escolha do problema de pesquisa, das relações com a comunidade científica e artística que, muitas vezes, produz impactos na forma como são conduzidas as disciplinas e na decisão interna das prioridades acadêmicas e administrativas.

Suas considerações esbarram na nítida dificuldade em se estabelecer limites entre liberdade estrutural-pedagógica e abordagem do conteúdo mínimo necessário na formação acadêmica de algumas profissões. Diante da instituição de competências profissionais comuns em todo o território nacional, surge o seguinte questionamento: poderia haver discrepância na formação técnica a partir da diversificação de estruturações curriculares, infraestrutura física e recursos humanos? Quais seriam os limites das particularidades contextuais? 


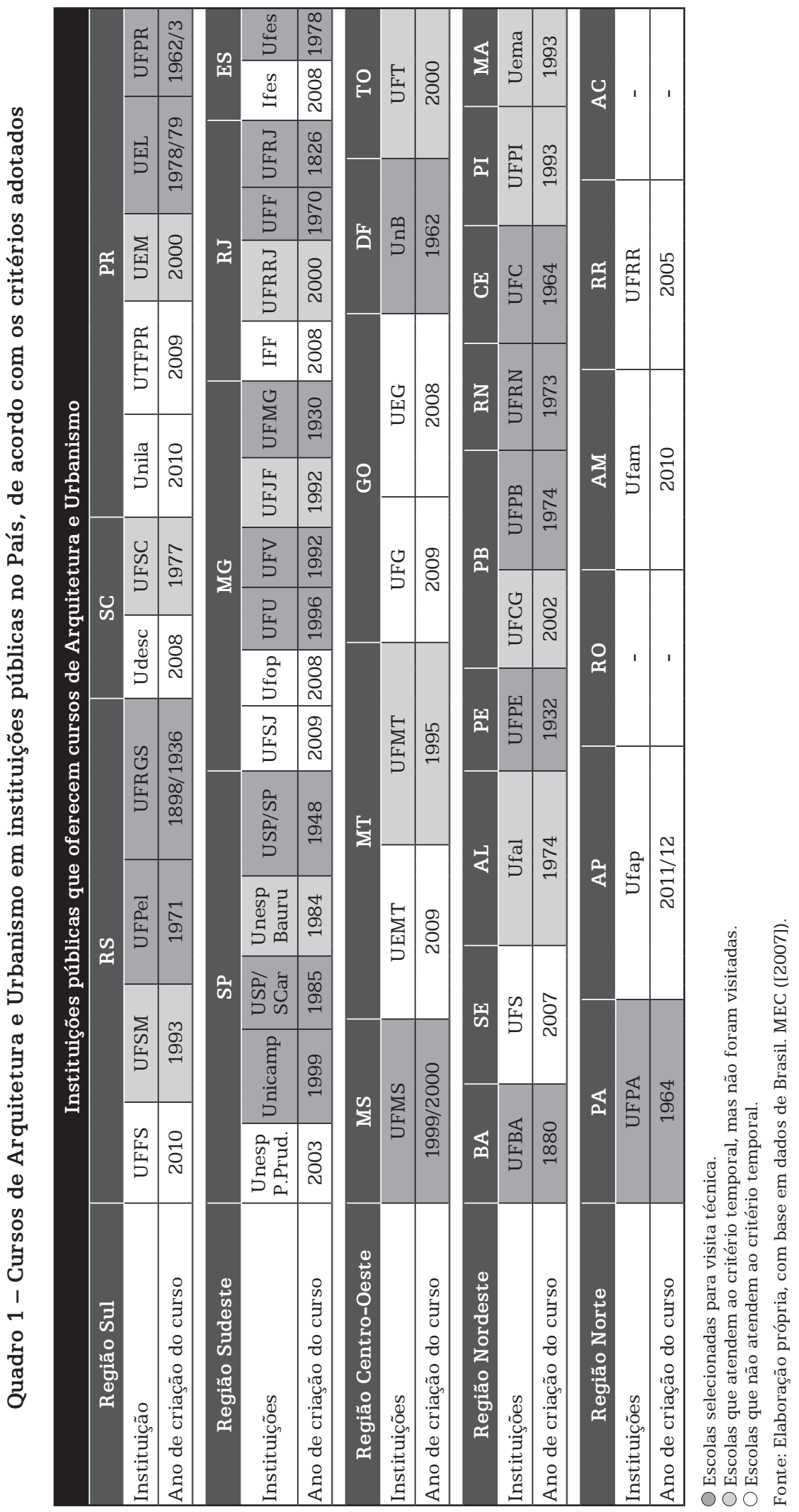




\section{Estrutura curricular e os conteúdos da área da Tecnologia da Construção}

Em muitos casos, a grade curricular não é considerada um instrumento importante para a promoção de mudanças significativas no ensino. No entanto, partindo da análise de diferentes propostas pelo País, verificou-se que essa questão não deveria ser subestimada, pois evidencia, documentalmente, algumas particularidades estruturais como: i) o desequilíbrio entre áreas e a relação direta entre grade e composição do quadro docente; ii) as alocações que revelam a existência ou não de estratégias pedagógicas por meio da conexão entre conteúdos e disciplinas; e iii) a liberdade propositiva e os indícios da heterogeneidade de formações acadêmicas entre os cursos pelo País.

Ao longo dos anos, o ensino de Arquitetura e Urbanismo esteve sujeito a diferentes processos regulatórios, na intenção de promover maior equilíbrio entre as áreas de concentração que compõem o currículo mínimo, como as recomendações da Carta de Ouro Preto de 1977, que defendia que o currículo mínimo deveria preservar a unidade na formação profissional em âmbito nacional e atender às mais amplas atribuições. Para isso, deveria ser evitada a tendência à formação de especializações, com defesa à formação generalista. Como proposta, esse documento sugeriu que as matérias abrangessem as seguintes áreas de conhecimento, com os respectivos percentuais de carga horária $(\mathrm{CH})$ : Planejamento e Projeto com 40\% da CH; Tecnologia e Instrumentação com 20\%; e Teoria e História com 20\%. Os 20\% restantes ficariam a critério de cada escola. Sobre valores destinados à área da tecnologia, Leite (2005) considera que o primeiro sinal de desprestígio da área tecnológica em relação às demais seria o tempo curricular dedicado, identificando que, a partir do currículo mínimo de 1969, a CH destinada às disciplinas de tecnologia decresce para $25 \%$ a $30 \%$ da $\mathrm{CH}$ total do curso. Quando comparados os dados da autora com as recomendações da Carta de Ouro Preto, nota-se que o desprestígio é ainda maior em 1977, quando sugerem apenas $20 \%$ do tempo curricular às disciplinas de cunho técnico-profissional.

Já na década de 1990, a segunda avaliação da Ceau trouxe considerações importantes sobre a área da tecnologia, algumas delas sobre o dramático cenário infraestrutural e técnico das escolas, levando à proposição de diretrizes que minimizassem tal problema e orientassem novas demandas a diversificarem suas metodologias acadêmicas, como a utilização de laboratórios experimentais ${ }^{8}$, de maneira a não restringirem o processo educacional apenas a aulas teóricas.

Ao longo do desenvolvimento deste trabalho, foram detectados indicativos de contínuo declínio, diante da diminuição gradativa da $\mathrm{CH}$ destinada à área tecnológica e o enxugamento do tempo destinado a essas disciplinas, levando a questionamentos sobre o distanciamento do plano teórico dos projetos pedagógicos e diretrizes curriculares em relação às proposições acadêmicas que atualmente estão sendo colocadas em prática.

\footnotetext{
8 Laboratórios experimentais são espaços voltados para atividades de natureza prática, como a manipulação de materiais e sistemas construtivos diferenciados (concreto, madeira, aço etc.), estruturas e demais atividades que envolvam a materialidade.
} 
Quando analisada a carga horária das escolas visitadas, verificou-se grande discrepância no número de créditos destinados às disciplinas de Tecnologia da Construção, com variação de 8 a 20 créditos, em que o mínimo não chega à metade do valor máximo encontrado (Gráfico 4). Quanto ao espaço que essa área ocupa no curso, ele varia de 3,7\% a 9\% (Gráfico 3). 0 cenário é parecido quando são analisados os dados referentes à $\mathrm{CH}$ de toda área da Tecnologia da Arquitetura (que engloba não apenas as disciplinas de Tecnologia da Construção, mas também Sistemas Estruturais, Instalações Prediais e Conforto Ambiental), ocupando de 19\% a 34\% dos créditos totais das disciplinas obrigatórias (Gráfico 1), com números que variam de 38 a 83 créditos destinados à área técnica (Gráfico 2). Os dados indicam que um terço das escolas visitadas destinam menos que $25 \%$ de sua $\mathrm{CH}$ para a área da Tecnologia da Arquitetura.

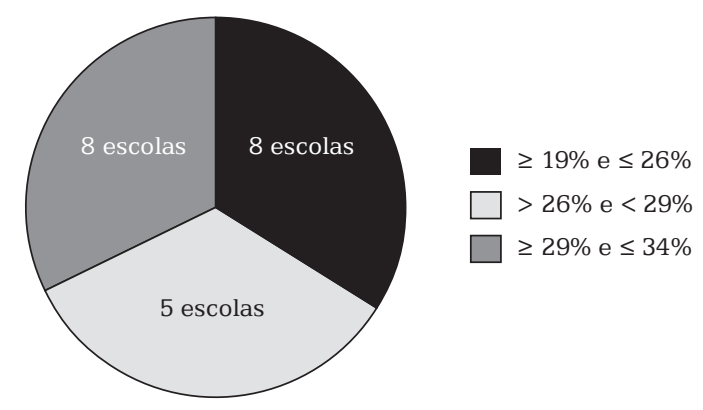

\section{Gráfico 1 - Área ocupada pela Tecnologia da Arquitetura nas grades curriculares}

Fonte: Laverde (2017, p. 257).

Nota: As escolas que adotam o mecanismo de fusão entre as áreas de Tecnologia da Construção e Sistemas Estruturais estão inclusas no grupo "não identificado".

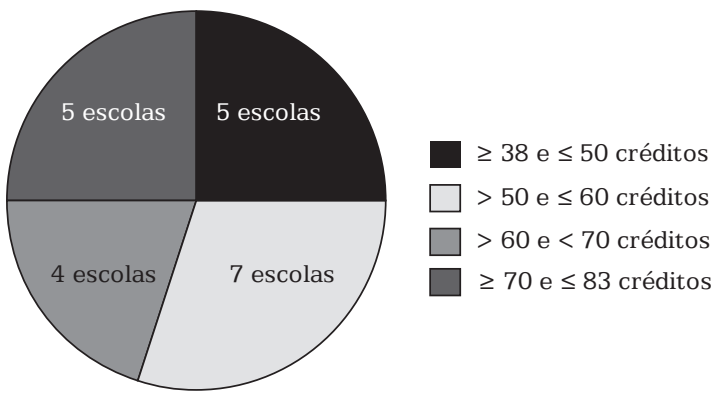

Gráfico 2 - Número de créditos destinados à área da Tecnologia da Arquitetura

Fonte: Laverde (2017, p. 257).

Nota: As escolas que adotam o mecanismo de fusão entre as áreas de Tecnologia da Construção e Sistemas Estruturais estão inclusas no grupo "não identificado". 


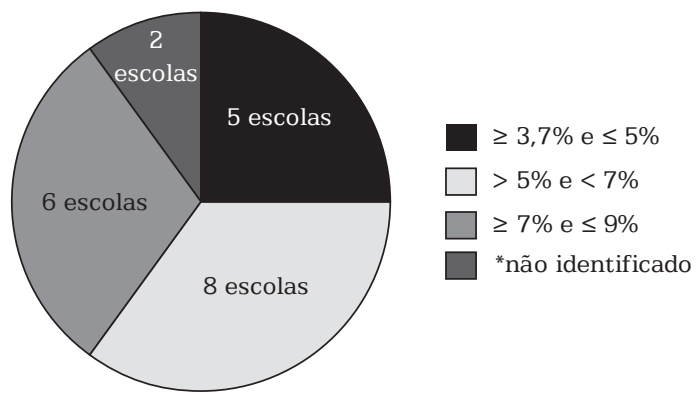
Gráfico 3 - Área ocupada pela Tecnologia da Construção de acordo
com as grades curriculares

Fonte: Laverde (2017, p. 257).

Nota: *As escolas que adotam o mecanismo de fusão entre as áreas de Tecnologia da Construção e Sistemas Estruturais estão inclusas no grupo "não identificado".

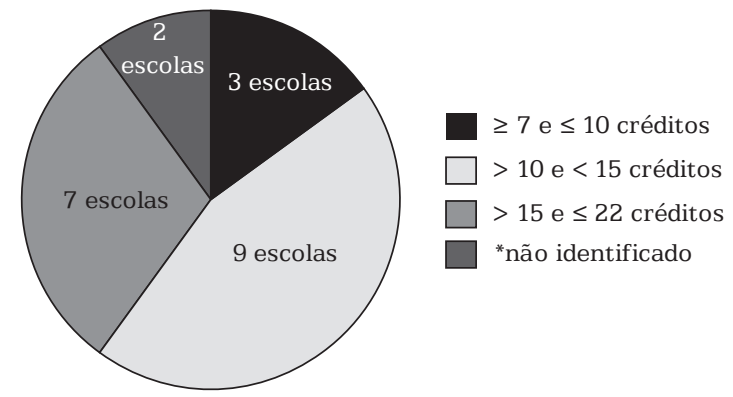

Gráfico 4 - Número de créditos destinados à área da Tecnologia da Construção

Fonte: Laverde (2017, p. 257).

Nota: *As escolas que adotam o mecanismo de fusão entre as áreas de Tecnologia da Construção e Sistemas Estruturais estão inclusas no grupo "não identificado".

As diferentes propostas curriculares e alocações revelam indicativos sobre a liberdade na estruturação curricular dos cursos, tendo em vista que são encontrados currículos que iniciam o conteúdo sobre Tecnologia da Construção no $1^{\circ}$ semestre, ou no $2^{\circ}$, no $3^{\circ}$, no $4^{\circ}$ e até mesmo a partir do $5^{\circ}$ semestre do curso. Sobre essa questão, foram apresentados diferentes pontos de vista sobre o momento ideal para ser iniciado. Nas escolas em que o ensino se inicia no $1^{\circ}$ ano, foi declarado que os alunos já possuem maturidade para receber o conteúdo voltado à Tecnologia da Construção, pois chegam muito bem preparados do vestibular, sendo uma estratégia importante para que o discente tenha uma visão generalista da profissão desde o início da formação - nesses casos, o $2^{\circ}$ ano também foi indicado como um bom momento. Esse posicionamento não foi compartilhado por alguns docentes que não tiveram a oportunidade de vivenciar esse tipo de experiência. Eles consideraram os alunos, até mesmo os do $2^{\circ}$ ano, imaturos para receber o conteúdo relativo à Tecnologia da Construção. $\mathrm{O}$ 
9 Infraestrutura física laboratorial refere-se às instalações físicas ou aos espaços experimentais dentro dos cursos, como laboratórios de materiais, canteiros de obras, canteiros experimentais, marcenarias e maquetarias. Em vários cursos visitados, essa infraestrutura é compartilhada com os cursos da Engenharia Civil devido aos custos de manutenção e otimização no uso de equipamentos. No caso das práticas acadêmicas, referem-se às atividades pedagógicas desenvolvidas nos espaços experimentais como desenvolvimento de modelos e protótipos, maquetes, ensaios físicos etc. ponto consensual relatado foi que a partir do $5^{\circ}$ período seria tardio para o início dessa abordagem.

Diante de propostas tão diversificadas para a área da Tecnologia da Construção, pode-se retomar a pergunta inicialmente introduzida: como alcançar a homogeneização da qualificação profissional nas diversas regiões do País e garantir as mesmas atribuições profissionais de caráter técnico diante de propostas curriculares tão diferenciadas?

Com base nos dados analisados, alguns recursos podem ser descartados, como a simples adoção de leis e documentos normativos, cuja dinâmica de discussão resulta em revisões e atualizações lentas e descompassadas com o que acontece na sociedade, pois não garantem que será alcançada a formação acadêmica necessária ao atendimento das futuras competências, assim como o formato normativo não assegura que o conteúdo presente no plano teórico do projeto pedagógico seja realmente cumprido pelas escolas.

\section{Infraestrutura física laboratorial ${ }^{9}$ e as práticas acadêmicas}

Quanto à forma de condução das atividades voltadas à Tecnologia da Construção, é de grande relevância o aspecto ligado ao modelo adotado pelas escolas quanto à responsabilidade das disciplinas dessa área, havendo influência direta entre este aspecto e as metodologias exploradas, assim como na utilização e configuração dos espaços experimentais, quando existentes. O Gráfico 5 refere-se à sintetização das situações encontradas quanto à responsabilidade das disciplinas da área da Tecnologia da Construção.

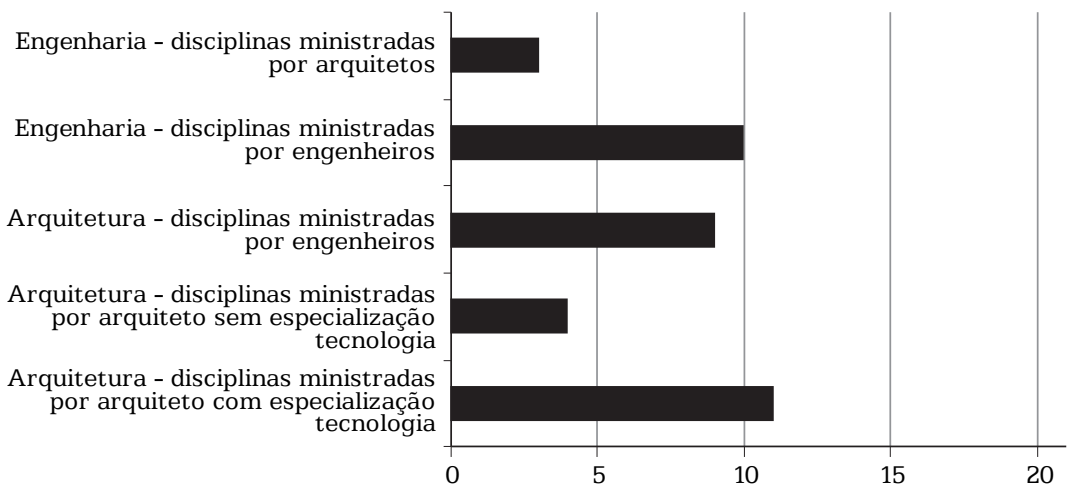

Gráfico 5 - Modelo atual adotado pelas escolas - curso para o qual são delegadas as disciplinas e perfil docente

Fonte: Laverde (2017, p. 264).

Os números mais representativos são de cursos em que as disciplinas da área da Tecnologia da Construção são ministradas por arquitetos com especialização nessa área, seguidos dos cursos em que as disciplinas são conduzidas por engenheiros pertencentes ao quadro docente do curso da Engenharia Civil. Posteriormente, estão os cursos de Arquitetura que 
possuem engenheiros em seus quadros docentes, sendo os responsáveis pela área da Tecnologia da Construção. Ao analisar a participação de cada perfil profissional (engenheiros e arquitetos) à frente das disciplinas, há uma média de participação equilibrada, $50 \%$ de arquitetos e $50 \%$ de engenheiros.

Observando o Gráfico 6 é possível identificar as principais metodologias pedagógicas empregadas na condução das disciplinas da Tecnologia da Construção nas escolas visitadas (além das aulas teóricas, que são empregadas em $100 \%$ das escolas), destacando-se as visitas técnicas em obra $^{10}$, seguidas da utilização de mostruário de materiais ${ }^{11} \mathrm{em}$ sala de aula. Posteriormente, está a análise de projetos técnicos ${ }^{12}$ e, em seguida, a realização de ensaios físicos ${ }^{13}$ em laboratório, sendo proporcionais os casos em que os ensaios são realizados pelos alunos com aqueles em que o técnico laboratorista é quem os realiza. A adoção de processos experimentais, como a construção de protótipos físicos, ainda é um recurso pouco utilizado pelas escolas visitadas, apresentando um número inexpressivo em relação às demais práticas pedagógicas.

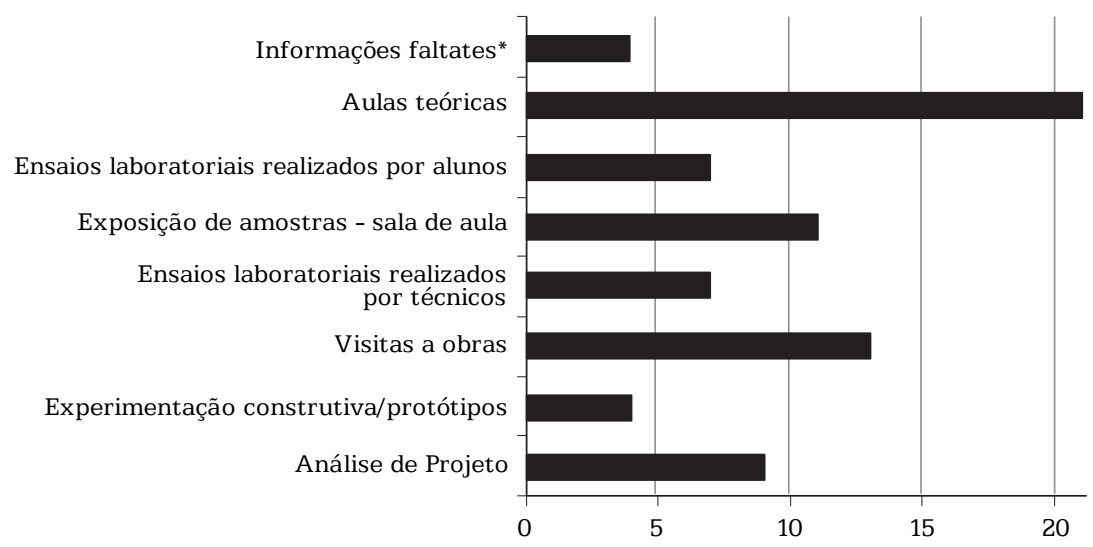

Gráfico 6 - Representatividade da metodologia pedagógica utilizada na abordagem do conteúdo das disciplinas de Tecnologia da Construção

Fonte: Laverde (2017, p. 267).

Nota: As informações faltantes referem-se aos casos nos quais não foi possível obter informações suficientes, geralmente em escolas em que um dos professores à frente das disciplinas não teve disponibilidade para participar da pesquisa.

Das 21 escolas visitadas, apenas duas têm em sua proposta curricular a obrigatoriedade do estágio em obra, sendo relatados, consensualmente, os resultados positivos dessa iniciativa.

Foi observado que as configurações dos laboratórios existentes muitas vezes estão diretamente associadas ao perfil docente à frente dessas práticas, pois, em muitos casos, a infraestrutura laboratorial foi adquirida com recursos provenientes de pesquisas individuais. O Gráfico 7 expõe os dados referentes aos tipos de espaços encontrados e sua relação com determinado curso (Engenharia Civil ou Arquitetura), dados estes que devem ser analisados de forma conjunta com o Gráfico 8.
10 As visitas técnicas em obra consistem no acompanhamento de obras em fase de construção com o monitoramento de profissionais engenheiros ou arquitetos.

11 Alguns cursos possuem mostruários de materiais, onde ficam expostos diferentes materiais construtivos, acervo visual.

12 Além do projeto arquitetônico, outros projetos complementares são necessários para a execução de uma obra, como o projeto estrutural, hidráulico, elétrico etc. Esses projetos técnicos precisam ser analisados e compatibilizados com os projetos arquitetônicos. Nesse caso, não há necessidade de espaços físicos diferenciados, na própria sala de aula é possível realizar esse tipo de atividade.

13 A realização de ensaios físicos ou ensaios técnicos laboratoriais é uma prática muito comum nos cursos de Engenharia Civil, e oferecida, em alguns casos, para os cursos de Arquitetura. Consiste geralmente no rompimento de corpos de prova para a análise das características dos materiais, detectando possíveis fragilidades. Os resultados podem influenciar nas escolhas dos materiais construtivos e também no dimensionamento das estruturas dos edifícios. Nessas atividades, há necessidade de equipamentos especiais e espaços infraestruturais adequados, devido a isso, muitas vezes são de uso compartilhado. 
14 Os laboratórios de maquetes e protótipos constituem-se em um dos espaços experimentais voltados à construção de modelos reduzidos e protótipos em escalas medianas. Trata-se de uma infraestrutura geralmente pertencente aos cursos de Arquitetura, e não voltada à manipulação de materiais de construção civil.

15 Os laboratórios de tecnologia da construção são, na maior parte dos casos, espaços experimentais voltados a ensaios físicos com materiais ou elementos construtivos, com análise laboratorial e rompimento de corpos de prova.

16 O termo "canteiro experimental" surgiu no início da década de 1990, na Faculdade de Arquitetura e Urbanismo da Universidade de São Paulo, tratando-se de um espaço experimental configurado como um espaço semelhante ao tradicional canteiro de obras, podendo ser coberto ou não, voltado à manipulação de materiais construtivos reais e protótipos em escala; não é voltado para a realização de ensaios físicos, mas pode ter o apoio de demais laboratórios.

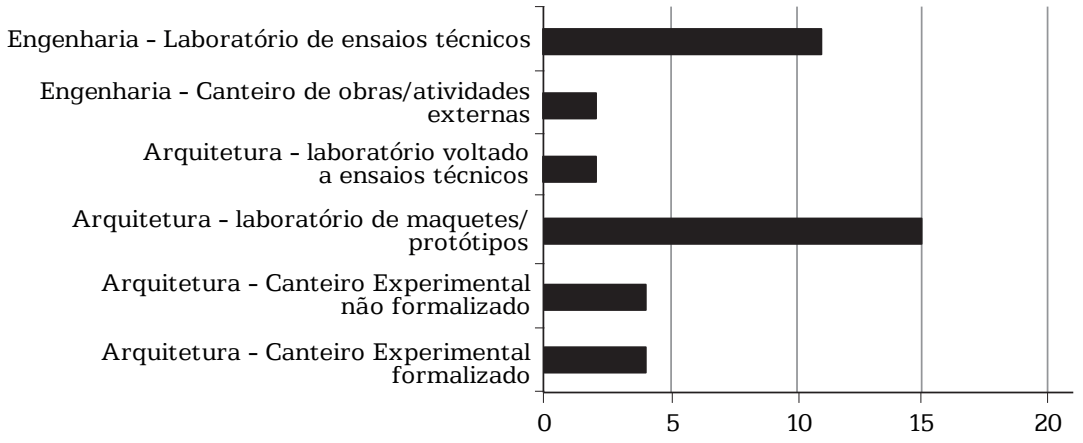

\section{Gráfico 7 - Caracterização da infraestrutura laboratorial na área da Tecnologia da Construção, quando existente}

Fonte: Laverde (2017, p. 269).

De acordo com os dados expostos no Gráfico 7, os laboratórios de maquetes e protótipos ${ }^{14}$ pertencentes aos cursos de Arquitetura aparecem com mais expressividade em relação aos demais, embora deva ser considerado que a maior parte deles é pouco utilizada pelas disciplinas da área da Tecnologia da Construção. Em segundo lugar, destaca-se a infraestrutura laboratorial pertencente aos cursos de Engenharia Civil, como os laboratórios da Tecnologia da Construção ${ }^{15}$, geralmente voltados a ensaios técnicos. Posteriormente, está o uso do canteiro experimental ${ }^{16}$ que, em todos os casos analisados, é utilizado exclusivamente pelo curso de Arquitetura. Foi observada proporcionalidade no número de escolas que possuem esse espaço formalizado junto ao curso e aquelas que utilizam espaços não formalizados para essa função. O número menos representativo refere-se tanto à utilização de espaços externos pertencentes à Engenharia Civil para a realização de atividades práticas como também ao de escolas de arquitetura que possuem laboratórios próprios voltados a ensaios técnicos (apenas dois em relação ao total de escolas visitadas).

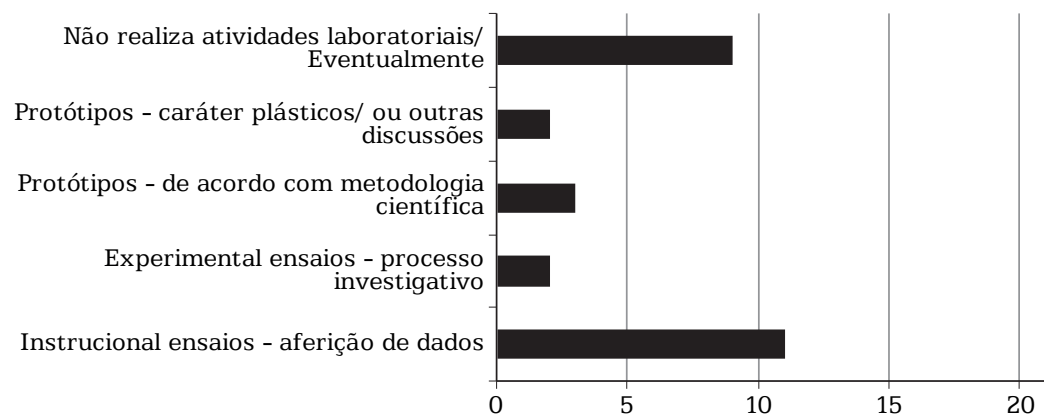

Gráfico 8 - Representatividade dos diferentes tipos de atividades laboratoriais encontradas

Fonte: Laverde (2017, p. 271). 
Analisando do Gráfico 8, é possível observar o número expressivo de cursos que exploram as atividades laboratoriais na forma de ensaios físicos ou técnicos, sendo geralmente voltados à aferição de dados. Em seguida, estão os cursos que não adotam atividades de cunho experimental em apoio à abordagem do conteúdo da área da Tecnologia da Construção ou, quando adotam, isso é feito de forma eventual e não sistemática. O mesmo gráfico também expõe o reduzido número de exemplos que adotam a execução de protótipos como atividade prática, sendo inexpressivos tanto os casos que se apoiam em metodologia científica para desenvolvê-los como os que não se apoiam. A utilização de ensaios físicos como processo investigativo se apresenta em número reduzido, com apenas duas escolas que adotam a metodologia laboratorial, tratando-se de experiências isoladas, assim como a confecção de protótipos.

A falta de espaços adequados, recursos contínuos e de carga horária compatível com as atividades laboratoriais tem dificultado o desenvolvimento dessas práticas no ensino, levando à conclusão de que há um distanciamento entre quem propõe e quem executa, portanto, entre o plano teórico dos projetos pedagógicos e os profissionais diretamente envolvidos com as disciplinas da área.

Retomando o Gráfico 7, é possível verificar que um número considerável de escolas utiliza infraestrutura compartilhada e pertencente aos cursos de Engenharia Civil, sendo poucos os laboratórios sob a administração do curso de Arquitetura (dois laboratórios dentro do conjunto de 21 escolas) com as mesmas características e voltados às práticas na área da Tecnologia da Construção. No caso dos laboratórios pertencentes à Engenharia Civil, foram somente considerados aqueles em que realmente ocorre o processo de compartilhamento, por meio de atividades voltadas ao ensino e realizadas de forma sistemática e não eventual, sendo contabilizados 11 laboratórios. Portanto, esse dado não está relacionado à existência de laboratórios nos cursos de Engenharia Civil, mas àqueles frequentados pelos graduandos dos cursos de Arquitetura durante as disciplinas.

Algo que chama atenção é que dos 13 laboratórios da área da Tecnologia da Construção utilizados (dois pertencentes ao curso de Arquitetura e 11 à Engenharia Civil), 100\% são de uso compartilhado com a pós-graduação e estão estruturados, prioritariamente, para dar suporte a pesquisas específicas, sendo esse o reflexo do atual sistema de apoio financeiro oferecido às universidades.

Essa situação tem estreita relação com a ausência de verba institucional para finalidades como manutenção e aquisição de infraestrutura física, sendo disponibilizadas aos pesquisadores outras vias para obtenção de recursos, como a participação em editais, que geralmente estão atrelados a uma pesquisa específica. Como a responsabilidade de estruturar e indicar prioridades fica a cargo do docente participante, os recursos adquiridos geralmente dão suporte à viabilização de suas pesquisas e, com isso, muitos laboratórios tomam configurações de acordo com essas condicionantes. Isso 
explica o reflexo da pós-graduação nas condições de ensino da graduação, pois o docente e pesquisador é um dos poucos profissionais que cria seu próprio ambiente de trabalho a partir das oportunidades oferecidas.

$\mathrm{O}$ fato de os espaços experimentais darem suporte à pós-graduação e, em muitos casos, serem estruturados com recursos provenientes da pesquisa (não integralmente) faz com que a prioridade de uso seja da pós-graduação, dificultando a apropriação desse espaço por parte dos graduandos. Foi relatada grande dificuldade no estabelecimento de estratégias que equilibrem a falta de espaço para a graduação e que mantenham o ponto positivo dessa proximidade, como a facilidade de os alunos terem contato com pesquisas de ponta, estimulando-os para a pesquisa na área da Tecnologia da Construção.

Em relação aos canteiros experimentais, foram compiladas informações sobre o cenário ideal para que as atividades práticas possam ser desenvolvidas na graduação, algo que vai além do simples reconhecimento sobre sua importância ou citação no plano do projeto pedagógico, estando a inserção dessas atividades condicionadas a ações reestruturantes profundas, tais como:

- Facilitar a divisão de turmas de maneira que haja relação numérica professor/aluno coerente às práticas laboratoriais, pois o número de alunos envolvidos no ensino em relação à pesquisa e extensão é muito discrepante. Além disso, a coordenação de curso deve disponibilizar carga horária compatível para a realização dessas atividades de natureza técnica/laboratorial.

- Viabilizar recursos financeiros para criação, operação e manutenção de espaços experimentais didáticos, já que verbas adquiridas por meio de pesquisas não podem ser direcionadas ao ensino. Observa-se que muitos cursos não tomam para si essa responsabilidade, ficando centralizada na figura docente, que, diante da incumbência de coordenar, estruturar e manter esse espaço sem o apoio necessário, acaba passando por um processo de desgaste e desestímulo.

- Evitar a centralização dessa responsabilidade em um único docente, havendo a necessidade de ampliar o quadro de professores da área técnica, para que haja rotatividade na coordenação dos espaços laboratoriais e a possibilidade de colaboração em pesquisas conjuntas. Ainda sobre essa questão, o fato de as atividades e espaços laboratoriais estarem geralmente condicionados à iniciativa pessoal docente pode dar margens para que essas experiências sejam interrompidas a qualquer momento, seja pela mudança de professor ou pela falta de apoio financeiro contínuo. Tal situação contribui para que as experiências acadêmicas, aos poucos, sejam desvinculadas do caráter científico, em que as atividades predominantemente empíricas podem ser uma resposta à falta de apoio do próprio curso. 


\section{Recursos humanos}

A formação do quadro docente possui associação direta com o histórico de cada curso, e suas estruturas organizacionais apresentam-se, geralmente, divididas em departamentos, núcleos, comissões etc., com base em um fator delimitador, como as áreas de concentração. A liberdade gerencial e decisória dada às unidades de ensino permitiu que os cursos se estruturassem ao longo dos anos de acordo com o entendimento dos atores em exercício, os quais foram estabelecendo as prioridades e o equilíbrio a ser alcançado em direção à formação generalista, objetivo nem sempre atingido. Diante dessa realidade, outros dados considerados relevantes foram levantados, na intenção de compreender a atuação e a influência docente no desenvolvimento dessa área específica, sendo constatada a existência de uma carência histórica de professores da área da Tecnologia da Construção na maioria dos cursos, dificultando a formação de grupos com objetivos e pesquisas comuns.

Há duas instâncias que precisam ser trabalhadas diante das diferentes estruturações encontradas, as que assumem e as que delegam a área técnica a outro curso, portanto, intra e intercursos. Com relação à primeira, o apoio necessário para que essas práticas aconteçam deve vir do próprio curso. Para isso, todos os atores, independentemente da área a que pertençam ou cargo que ocupem, devem compreender a dimensão das variáveis que influenciam na existência das atividades laboratoriais, que vão desde a estrutura curricular até a necessidade de recursos humanos e financeiros compatíveis para sua implantação. Sobre o segundo tipo de estruturação, no caso de os cursos delegarem essa responsabilidade, foi observada falta de diálogo entre os cursos de Arquitetura e Engenharia Civil, evidenciada pela dificuldade no reconhecimento das responsabilidades e sistemática laboratorial por parte dos cursos de Arquitetura. O diálogo entre os parceiros permite que sejam oferecidas as informações necessárias sobre as particularidades do curso que devem ser atendidas.

Além dos docentes, os técnicos laboratoristas também têm uma participação efetiva no desenvolvimento da área da Tecnologia da Construção, sendo observado que o principal gargalo é o reduzido número de profissionais atuando nessa função. Esse problema é vivenciado tanto pelos cursos de Engenharia Civil como de Arquitetura e Urbanismo, sendo mais dramático neste último, pois apenas quatro dos cursos visitados possuem técnicos para o auxílio nas atividades da área da Tecnologia da Construção. A escassez de profissionais tem sido agravada devido às aposentadorias sem a devida reposição e pelo aumento do número de alunos tanto da graduação como da pós-graduação, não sendo a relação numérica de técnicos e docentes acompanhada proporcionalmente pelo aumento da oferta de vagas para alunos.

Portanto, há um conjunto de ações individuais e coletivas articuladas entre si que colaboram para uma cultura voltada à valorização de determinado eixo, vinculadas, às vezes, a uma disputa de projeto 
universitário e de escola de arquitetura, que perpassa desde a estruturação curricular até a composição dos recursos humanos e físicos.

\section{Considerações finais}

Alicerçado nos dados levantados, obtidos nas fontes documentais e ao longo das visitas técnicas aos 21 cursos de Arquitetura pelo País (totalizando $64 \%$ do número de escolas de arquitetura inseridas em instituições públicas), foi delineado um panorama nacional sobre o atual cenário da área da Tecnologia da Construção, possibilitando atualizar as publicações existentes com mais precisão, algo que dificilmente seria possível por meio de outros recursos metodológicos, como a aplicação de questionários, preenchimento de formulários, entrevistas a distância, entre outros.

Sobre o cenário encontrado, foram identificadas dificuldades voltadas tanto à implantação como à sustentação dos espaços experimentais da área da Tecnologia da Construção, sendo recorrentemente declarada, ao longo das visitas técnicas, a falta de reconhecimento dos próprios cursos sobre a importância dessas práticas no processo de formação. Há estreita relação entre esse cenário e a formação docente, sendo constatado que muitas gerações de professores foram formadas em ambientes nos quais a experimentação construtiva não era adotada de forma sistemática como recurso didático. A ausência das práticas mencionadas ao longo da formação desses atores pode vir a influenciar diversas ações reestruturantes direcionadas a favorecer a implantação dessas experiências. Em alguns casos, cria-se o entendimento de que tais práticas são dispensáveis e que a área da Tecnologia da Construção pode ser desenvolvida sem infraestrutura laboratorial, apenas com abordagem teórica, distanciando o aluno da realidade profissional.

A avaliação dos cursos realizada pela Ceau, em meados da década de 1990, foi um momento importante de autocrítica, de olhar para si e ver como estava a situação nacional, resultando na posterior obrigatoriedade da existência de laboratórios e canteiros na área da Tecnologia da Construção. Contudo, o que se constatou ao longo dos anos em diversas escolas foi a implantação de alguns espaços experimentais desprovidos de infraestrutura mínima para o desenvolvimento de atividades práticas, sendo comum a implantação de espaços adaptados e inadequados, apenas para atender a uma demanda legal. Sendo assim, a essência pedagógica da experimentação foi pouco explorada ao longo dos anos.

Essas evidências revelam que nem mesmo as diretrizes curriculares, estabelecidas com base nos levantamentos realizados pela Ceau, motivaram a realização de mudanças significativas relacionadas à adoção de práticas experimentais, ficando claro que esse assunto deveria ser conduzido de acordo com a complexidade das variáveis envolvidas, que não se resumem à existência de espaço físico, que, embora possa levar ao cumprimento de uma exigência legal, ao longo do tempo pode vir a não cumprir sua verdadeira função. 
As considerações supracitadas revelam a ampla responsabilidade dos próprios cursos no desenvolvimento da área da Tecnologia da Construção, e, embora os dados levantados pelas Ceaus e suas resultantes normativas não tenham atingido grandes resultados em longo prazo, essa significativa iniciativa governamental pode ser resgatada e seus dados contrapostos aos demais levantados neste trabalho para o delineamento de políticas públicas mais efetivas, perpassando os seguintes aspectos:

- Fiscalização: um possível fato que acarretou o insucesso das ações resultantes dos levantamentos realizados pelas Ceaus foi o tratamento dado aos resultados, além do longo intervalo de duas décadas existente entre os dois levantamentos (décadas de 1970 e 1990). As observações levantadas pelas Ceaus se configuraram apenas em documentos e regulamentos normativos, sem, no entanto, ocorrerem fiscalizações efetivas por parte dos órgãos governamentais competentes sobre a implantação dessas medidas recomendadas, algo que orientaria a política interna das escolas sobre a condução da área da Tecnologia da Construção, como a proposição de $\mathrm{CH}$ compatível para a realização de atividades práticas, a implantação de infraestrutura obrigatória e a existência de número adequado de professores e técnicos. No entanto, além da fiscalização, dever-se-ia oferecer às escolas apoio na forma de informações sobre a configuração mínima ou ideal da infraestrutura e recursos para a promoção da formação na área da Tecnologia da Construção.

- Recursos financeiros: a maior parte dos recursos destinados às atividades de ensino são verbas institucionais, não sendo possível a obtenção de recursos por meio de projetos de pesquisa e extensão. Devido à necessidade de as práticas laboratoriais serem sustentadas por investimentos contínuos, deveria haver, por parte dos órgãos competentes, a garantia de recursos especiais para o desenvolvimento de atividades dessa natureza devido ao elevado número de alunos no ensino, diferentemente da pesquisa e extensão. Para isso, é necessário que ações articuladoras sejam empreendidas por entidades como o Conselho de Arquitetura e Urbanismo (CAU), a Associação de Ensino em Arquitetura e Urbanismo (Abea) e até mesmo o próprio setor da construção civil (devido à estreita relação entre a área e as atividades profissionalizantes) junto aos órgãos governamentais competentes.

- Recursos humanos: a influência da composição do quadro docente no desenvolvimento da área da tecnologia indica a necessidade de maior equilíbrio na representatividade desses profissionais junto aos processos decisórios internos, evitando que a área seja integralmente delegada aos cursos da Engenharia Civil. Outro ponto importante seria a garantia da oferta de técnicos laboratoristas, com o oferecimento de capacitação e especialização adequada em diferentes localidades do País. A necessidade de capacitação se 
estende aos cargos administrativos, sendo considerada de extrema relevância a oferta institucional de cursos de capacitação na área de gestão. Deve-se, portanto, garantir que os cursos tenham em sua composição profissionais capacitados para as atividades na área da experimentação construtiva, havendo a necessidade de maior apoio e controle governamental para que esse aspecto seja atendido.

Diante do complexo entrelaçamento das particularidades inerentes à área da Tecnologia da Construção, os espaços e as práticas experimentais demandam grande esforço e dedicação por parte dos atores, que, consequentemente, envidam maior tempo para condução e sustentação dessas atividades. Dessa forma, tanto o curso como os órgãos educacionais competentes precisam (re)conhecer as especificidades envolvidas e os recursos requeridos, para que os docentes da área técnica possam assumir essa empreitada com o apoio necessário, evitando o processo de desgaste e desestímulo, como visto ao longo das entrevistas.

Embora seja uma infraestrutura desejável, a existência de espaços experimentais exclusivos e voltados à realização de atividades práticas torna-se apenas um detalhe diante de outros problemas que diretamente impactam na estruturação da área da Tecnologia da Construção. Além disso, nos casos em que não haja condições, a curto prazo, para a implantação de infraestrutura exclusiva junto aos cursos, outras estratégias podem ser adotadas na abordagem do conteúdo sobre a materialidade, como a utilização de espaços compartilhados, o estágio obrigatório em obra e outras ações. A diversidade de práticas pedagógicas encontradas revela que a conjuntura de estratégias também pode levar a resultados satisfatórios e complementares, podendo ser menos onerosos em relação aos canteiros experimentais que não têm por base métodos científicos. Além das considerações supracitadas sobre políticas públicas, o processo de autoavaliação de cada escola pode levar à obtenção de pistas sobre os caminhos mais adequados para a realização de experiências criativas e promissoras de acordo com cada realidade contextual.

\section{Referências}

ASSOCIAÇÃO BRASILEIRA DE ESCOLAS DE ARQUITETURA. Carta de Ouro Preto. São Paulo, [1978]. Disponível em: <http://www.aairs.com. br/CARTA_DE_OURO_PRETO.pdf >. Acesso em: 22 jul. 2020.

BAYL-SMITH, M. BuildAbility: the future of construction education. New South Wales: New South Wales Architects Registration Board, 2011. (Byera Hadley Travelling Scholarships Journal Series). Research report. 
BRASIL. Conselho Federal de Engenharia, Arquitetura e Agronomia (Confea); Instituto Nacional de Estudos e Pesquisas Educacionais Anísio Teixeira (Inep). Trajetória e Estado da Arte da formação em Engenharia, Arquitetura e Agronomia: Arquitetura e Urbanismo. Brasília: Confea; Inep, 2010. v. 10.

BRASIL. Ministério da Educação (MEC). Diagnóstico das condições de ensino e pesquisa em Arquitetura e Urbanismo no Brasil - 1974. Brasília: MEC, 1977.

BRASIL. Ministério da Educação (MEC). Perfis da área \& padrões de qualidade: expansão, reconhecimento e verificação periódica dos cursos de arquitetura e urbanismo. Brasília: MEC, 1995.

BRASIL. Ministério da Educação (MEC). Cadastro Nacional de Cursos e Instituições de Educação Superior. Brasília, [2007]. Disponível em: $<$ http://emec.mec.gov.br >. Acesso: 20 jul. 2020.

FICHER, S. Os arquitetos da Poli: ensino e profissão em São Paulo. São Paulo: EdUSP, 2005.

GRANDE, N. Arquitetura e tecnologia na crise da cultura tectônica. In: CANNATÀ, M.; FERNANDES, F. A tecnología na arquitectura contemporânea: Dominique Perrault, Baumschlager \& Eberle, Mansilla + Tuñón, Carrilho da Graça. Lisboa: Estar, 2000.

GRAZZIA, S. et. al. Configuração de laboratórios de Tecnologia da Construção e de Sistemas Estruturais. In: CONGRESSO NACIONAL DA ASSOCIAÇÃO BRASILEIRA DE ENSINO DE ARQUITETURA E URBANISMO, 9., 1999, Londrina. Anais... Londrina: Ética para o III Milênio; Abea, 1999.

LAVERDE, A. Os espaços experimentais das escolas públicas do Brasil: realidade ou utopia? 2017. $320 \mathrm{f}$. Tese (Doutorado em Arquitetura) Faculdade de Arquitetura e Urbanismo, Universidade de São Paulo, São Paulo, 2017.

LEITE, M. A. D. F. A. A aprendizagem tecnológica do arquiteto. 2005. $384 \mathrm{f}$. Tese (Doutorado em Arquitetura) - Faculdade de Arquitetura e Urbanismo, Universidade de São Paulo, São Paulo, 2005.

LES GRANDS ateliers: un outil pour la construction de demain. Villefontaine, 2017. Disponible en: <http://www.lesgrandsateliers.org/ TPL_CODE/TPL_MEDIATHEQUEDOC >. Accès en: 22 jul. 2020.

LOPES, J. M. A. Quando menos não é mais: tectônica e o ensino tecnológico da Arquitetura e Urbanismo. In: ENCONTRO DA ASSOCIAÇÃO NACIONAL DE PESQUISA E PÓS-GRADUAÇÃO EM ARQUiTETURA E URBANISMO, 3., 2014, São Paulo. Anais... São Paulo: Anparq, 2014. 
MATTAR, F. N. Pesquisa de marketing. São Paulo: Atlas, 1996.

MONTEIRO, A. M. R. G. et. al. (Org.). A construção de um novo olhar sobre o ensino de Arquitetura e Urbanismo no Brasil: os 40 anos da Associação Brasileira de Ensino de Arquitetura e Urbanismo. Brasília: Associação Brasileira de Ensino de Arquitetura e Urbanismo, 2013.

MOTTA, F. Subsídios para relatório sobre ensino de Arquitetura UIAUNESCO, 1974. In: ASSOCIAÇÃO BRASILEIRA DE ESCOLAS DE ARQUITETURA. Sobre a história do ensino de Arquitetura no Brasil. São Paulo: Associação Brasileira de Ensino de Arquitetura e Urbanismo, 1977. p. 138-143

SANTOS JÚNIOR, W. R. O currículo mínimo no ensino de Arquitetura e Urbanismo no Brasil: 1969-1994. 2001. Tese (Doutorado em Arquitetura) - Faculdade de Arquitetura e Urbanismo, Universidade de São Paulo, São Paulo, 2001.

SELLTIZ, C. et al. Métodos de pesquisa nas relações sociais. Tradução: Dante Moreira Leite. São Paulo: EdUSP, 1975.

TAMASHIRO, H. A. Entendimento técnico-construtivo e desenho arquitetônico: uma possibilidade de inovação didática. 2010. 183 f. Tese (Doutorado em Arquitetura) -Escola de Engenharia de São Carlos, Universidade de São Paulo, São Carlos, 2010.

TRIGUEIRO, M. G. S. Universidades públicas: desafios e possibilidades no Brasil contemporâneo. Brasília: UnB, 1999.

UNIVERSITY OF STUTTGART. ICD ITKE Research Pavilion 2013-14: production of Institute for Computational Design (ICD) and Institute of Building Structures and Structural Design (ITKE) of the University of Stuttgart. Stuttgart, 2014. Available in: <https://www.itke.uni-stuttgart. de/research/built-projects/landesgartenschau-exhibition-hall-2014/>. Access in: 22 July 2020.

VACCARI, M. Shigeru Ban Studio e projetos. [Kyoto], 2013. Disponível em: <http://www.usp.br/noah/wp-content/uploads/2013/08/MirianVaccari_Shigeru-Ban.pdf $>$. Acesso em: 22 jul. 2020.

Recebido em 18 de fevereiro de 2019.

Aprovado em 5 de junho de 2020.

(1) \$ste é um artigo de acesso aberto distribuído nos termos da licença Creative Commons do tipo BY-NC. 